\title{
Developing a Conceptual Framework for Modeling Deviant Cyber Flash Mob: A Socio-Computational Approach Leveraging Hypergraph Constructs
}

\author{
Samer Al-khateeb \\ University of Arkansas, Little Rock \\ Nitin Agarwal \\ University of Arkansas, Little Rock
}

Follow this and additional works at: https://commons.erau.edu/jdfsl

Part of the Computer Engineering Commons, Computer Law Commons, Electrical and Computer Engineering Commons, Forensic Science and Technology Commons, and the Information Security Commons

\section{Recommended Citation}

Al-khateeb, Samer and Agarwal, Nitin (2014) "Developing a Conceptual Framework for Modeling Deviant Cyber Flash Mob: A Socio-Computational Approach Leveraging Hypergraph Constructs," Journal of Digital Forensics, Security and Law. Vol. 9 : No. 2 , Article 10.

DOI: https://doi.org/10.15394/jdfsl.2014.1175

Available at: https://commons.erau.edu/jdfsl/vol9/iss2/10

This Article is brought to you for free and open access by

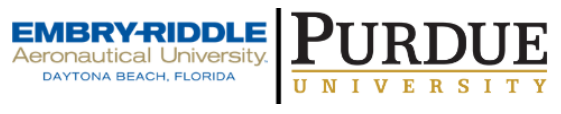
the Journals at Scholarly Commons. It has been accepted for inclusion in Journal of Digital Forensics, Security and Law by an authorized administrator of Scholarly Commons. For more information, please contact commons@erau.edu.

(c)ADFSL 
@) (-) This work is licensed under a Creative Commons Attribution 4.0 International License

\title{
DEVELOPING A CONCEPTUAL FRAMEWORK FOR MODELING DEVIANT CYBER FLASH MOB: A SOCIO-COMPUTATIONAL APPROACH LEVERAGING HYPERGRAPH CONSTRUCTS
}

\author{
Samer Al-khateeb, and Nitin Agarwal \\ Department of Information Science \\ University of Arkansas at Little Rock \\ Little Rock AR 72204, USA \\ \{sxalkhateeb, nxagarwal\}@ualr.edu
}

\begin{abstract}
In a Flash Mob (FM) a group of people get together in the physical world perform an unpredicted act and disperse quickly. Cyber Flash Mob (CFM) is the cyber manifestation of flash mob coordinated primarily using social media. Deviant Cyber Flash Mob (or, DCFM) is a special case of CFM, which is categorized as the new face of transnational crime organizations (TCOs). The DCFM phenomenon can be considered as a form of a cyber-collective action that is defined as an action aiming to improve group's conditions (such as, status or power). In this paper, we conduct a conceptual analysis of the DCFMs and model the factors that lead to success or failure with groundings in collective action and collective identity formation theories. Mathematical constructs of hypergraph are leveraged to represent the complex relations observed in the DCFM social networks. The model's efficacy is demonstrated through a test scenario.
\end{abstract}

Keywords: cyber crime, cyber security, deviant cyber flash mob DCFM, collective action, social media, predictive model.

\section{INTRODUCTION}

The widespread use of contemporary forms of information and communications technology (ICTs), such as social media, have transformed the way people interact, communicate, and share information. This has afforded a fundamental paradigm shift in the coordination abilities of people leading to manifestations of cybercollective actions (Agarwal, Lim, \& Wigand, 2014; Agarwal et al., 2012) in various forms, whether they are social movements for sociopolitical transformation, campaigns for better governance through citizen journalism and engagement, or flash mobs (FM) for promoting a cause or simply entertainment. A flash mob (FM) is a group of individuals who get together in a pub- lic place, perform an unusual act, and quickly disperse. These group acts are often conducted for the purposes of entertainment, satire, and artistic expression. (Oxford-Dictionary, July 8, 2004). The first flash mob was created in Manhattan in 2003, by Bill Wasik, who is a senior editor of the Harper's Magazine. The purpose of that flash mob as Wasik claimed was "a social experiment designed to poke fun at hipsters and to highlight the cultural atmosphere of conformity and of wanting to be an insider or part of the next big thing" (Wasik, December 16, 2011). There are many examples of flash mobs happened after 2003 i.e. Dare to fight a ninja, Freeze mob in Paris, and Happy Birthday for a bus driver,.. etc (Kirkland, December 21, 2011). 


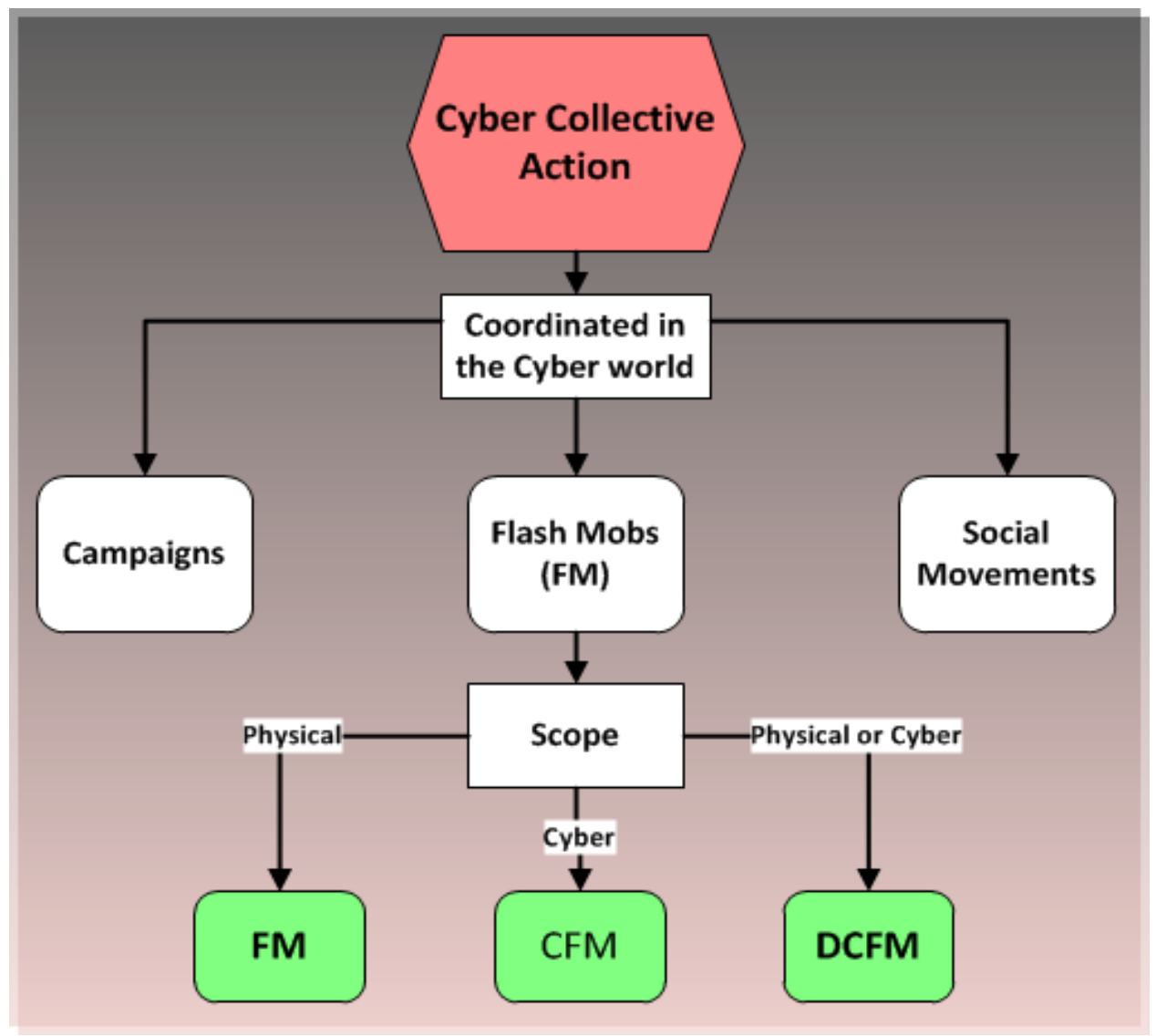

Figure 1 Different Forms and Scopes of Cyber Collective Action, i.e., Flash Mobs (FM), Cyber Flash Mobs (CFM), and Deviant Cyber Flash Mobs (DCFM).

Some FMs were organized locally some of them internationally like the largest pillow fight flash mob which was called the International Pillow Fight Day. It took place on March 22, 2008 and it was recorded as the world's largest flash mob to date with over 25 cities participating around the globe (Reporter, April 4, 2011).

Cyber flash mobs (CFM) which are the cyber manifestation of flash mobs (see Figure 1), are known to be coordinated via social media, telecommunication devices, or viral emails (Nicholson, 2005). CFMs are self-organized groups of individuals who get together in cyberspace, perform an unpredicted act, and quickly disperse. Some of the CFMs are organized for entertainment purpose others can lead to robberies and thefts. The latter form of CFM is known as "Deviant CFM" such as the "Bash Mob" that happened in Long Beach,
CA in July 9, 2013 (Holbrook, July 19, 2013). Deviant CFM (or, DCFM) can be considered as a form of a cyber-collective action that is defined as an action aiming to improve a group's conditions (such as, status or power) (Ludlow, January 13, 2013). These DCFMs are categorized as the new face of transnational crime organizations (TCOs) (e.g., "hacktivist" groups) that can pose significant risks to political, social, and economic stability (Ackerman et al., 2013). The DCFM activities can stretch beyond the cyberspace, i.e., in physical spaces. For example, there are two very well known DCFMs that are mentioned here to highlight the differences in the scope of their activities:

1. The Comment Flash Mob. (Digits, February 21, 2012) The case refers to a February 2012 attack on a number of Wall Street Journal (WSJ)s Facebook pages by 
one of the groups that claimed to be linked to the Anonymous hacking group. The attacks were a result of the allegations by a German WSJ article that suggested the group had links with Al-Qaeda. The group solicited participation in the attack and requested the following message be promoted (by copy and pasting on several WSJ pages), along with strategies to avoid getting blocked while posting the message, "Dear editors of the German Wall Street Journal, you equated Anonymous with AlQaeda in your February 2012 article and the related coverage. With this type of coverage you may be able to stir up fear in the United States, but not in the land of poets and thinkers! With this comment, we oppose the deliberate dissemination of false information and express our displeasure with your lobby journalism. We are Anonymous. We are millions. We do not forgive. We do not forget. Expect us!"

The attack quickly spread to other German WSJ Facebook pages before going viral and affecting the main WSJ Facebook pages. According to reports, the attacks subsided in a few hours affecting user experience in numerous ways, before the group turned their attention to a Saudi blogger activist.

2. The Flash Mob Cyber Heist. (Dye \& Finkle, May 9, 2013) A more disturbing example is the $\$ 45$ million "flash mob cyber heist" that took place in two phases on Dec 21, 2012 (\$5 million) and February 19, 2013 (\$40 million) in 27 countries. Hundreds of "cashers" around the globe armed with prepaid debit cards (that were manipulated by hackers to have no withdrawal limits) hit the ATMs. Full technical details of the cyber heist are still obscure, however, cyber security experts believe such acts typically come together in Internet forums, where hackers can exchange or sell information and recruit others. A great deal of technical groundwork had to be laid to create the complex network access needed but the final stage was quick as a swarm of individuals hit machines and raked in the cash.

The entire operation is conducted in multiple stages. In the early stages, one or more geeks install computer viruses inside networks, then spend days or weeks gathering detailed information about a bank's operations as they plan the job. As they get ready to carry out the job, "carders" produce fake payment cards by coding the stolen account numbers onto magnetic strips. Those cards are distributed to large numbers of "cashers", who withdraw money from ATMs. "Mules" help move the loot across borders, sometimes in the form of luxury goods that they purchase with the cash. The ringleaders, who rake in the biggest profits, typically are at the least risk of getting caught, while the carders, cashers and mules take on the highest risk of arrest. After making seven arrests in the New York City, who comprised the New York cell of the operation, US Attorney for the Eastern District of New York, Loretta Lynch said, "the gangs moved at the speed of data across the Internet."

These DCFMs are interesting not only for scientific research, but also pose non-negligible concerns for public safety and national security. Therefore, in this study, we propose to seek answers to the following research question:

- How decentralized on-line individual actions transform into collective actions resulting in Deviant Cyber Flash Mob (DCFM) behaviors?

Consequently, this question leads us to seek answers for:

1. What are the necessary conditions that lead to the emergence of these phenomena?

2. Can we explain the motivation needed for the subsistence of such coordinated acts?

3. How can we build predictive models of DCFM behaviors?

Seeking answers to the aforementioned questions, we make the following contributions in this article: 
1. We define an emerging socio-technical behavior, viz., Deviant Cyber Flash Mob (DCFM) observed among cyber crimes and networked violent groups.

2. We identified the factors that lead to the success or failure of the DCFM and developed postulates.

3. We designed a socio-computational model based on these postulates to predict the trajectory of a DCFM advancing our understanding of the emerging socio-technical behavior.

4. We used the hypergraph notation to represent the inherently multidimensional and supra-dyadic nature of the interactions manifested by the complex DCFM phenomenon.

5. We present a DCFM scenario to study the efficacy of the proposed model.

We envision the research will help develop cybersecurity strategies dealing with DCFM behaviors at a fundamental social and behavioral level, contributing towards a synergistic advancement of the various disciplines for the modern Information and Communication Technologies (ICT) landscape.

Rest of the article is organized as follows. Theoretical background of the research is discussed in Section 2. Section 3 presents the research methodology including mathematical framework of the model, in-depth treatment of factors governing success and failure of DCFM, and the proposed conceptual framework. A DCFM test scenario is presented in Section 4 to examine the model's efficacy. Section 5 concludes the study with possible future research directions.

\section{LITERATURE REVIEW}

The phenomenon of Deviant Cyber Flash Mob (DCFM) increased rapidly since its inception. As soon as the mobile devices and texting became common in the early 2000 s, people realized the potential of these technologies to mobilize individuals to act in a coordinated manner, possibly disruptively and then quickly disperse
(Cyveillance, December 2, 2013). Theories such as collective action (Coleman, 1973), collective identity formation (Klandermans et al., 2002) (Melucci, 1996), collective decision (Coleman, 1966), social capital (Coleman, 1966), and network modularity (Newman, 2006) have often been used to explain the group dynamics underlying collective behavior phenomena. These theories and concepts have been studied in the past by many researchers, but to the best of our knowledge never been used to study DCFMs. Understanding and modeling DCFMs is a challenging an important research problem that involves identifying the factors that could explain motivation behind this phenomenon. A systematic analysis of the factors would afford modeling capabilities to predict success or failure for a DCFM. Our work is geared toward this direction. More specifically, by leveraging the collective action theory, we develop an analytical/conceptual framework that operationalizes the identified factors into a socio-computational model capable of predicting the outcome of DCFMs. Next, we briefly review literature on collective action theory.

Collective action is defined as all activity of common or shared interest among two or more individuals (Olson, 1977). Collective action theories can be traced back to Ronald Coase's (Coase, 1937) economic explanation on why individuals are willing to form companies, and partnerships in business trading other than making bilateral contracts between individuals. Many years later, there are many collective action theories developed such as the Neutrality Theorem (Warr, 1982, 1983), Club Theory (Sandler \& Tschirhart, 1980), Folk Theorem (Rubinstein, 1979), and the most eminent one, Rational Choice Theory (Becker, 1976). As the collective action studies developed, many other approaches emerged such as the Resource Mobilization Theory (Zald \& McCarthy, 1979; Kerbo, 1982; Ferree, 1992) that emerged in the 1970s and early 1980s. This theory was the most influential approach in explaining the success of collective action. However, this theory and the Rational choice theory were criticized for failing to answer the question as to how social meaning is constructed and how 
it works as a driving force for action. As a reaction to this critique the New Social Movement Theory (NSMT) emerged. This theory associates actions with belief systems that revolve around a set of values and symbols that are specific to the group (Snow et al., 1986; Johnston et al., 1994).

In the book by James S. Coleman "The mathematics of Collective Action" (Coleman, 1973), Coleman proposed a framework for collective action and provided 25 mathematical definitions. Concepts such as power, control, utility, and interest, defined by Coleman are borrowed in our proposed model. The concepts have been appropriately modified to suit the cyberspace, especially for the DCFM behavior. Contributions of this paper include revisiting theories and concepts that have been studied in social science and assess their applicability to the cyberspace. Next, we present the methodology driven by social science theories on collective action and collective identity formation, to help develop the conceptual framework to analyze the DCFM. To the best of our knowledge, this is the first study examining the DCFM behavior with groundings in social science theories.

\section{METHODOLOGY}

In this article, we focus on advancing our understanding of DCFMs by analyzing the factors that lead to their success or failure. We develop an analytical model that is capable of predicting the outcome of a DCFM. Sociological theories of collective action and collective identity formation are adopted to model the dynamics of DCFMs. The analytical framework grounded in these sociological theories helps explain the motivation needed to sustain such highly coordinated acts and assimilate factors pertaining to collective success/failure. Table 1 shows the symbols that we use in our methodology with their meaning.

\subsection{Modeling DCFM}

We provide a conceptual understanding of the model for predicting DCFM outcome in this section. Below, we list high level relations between the factors that help us assess the motivation needed to sustain coordinated acts such as the DCFM and eventually lead to its success or failure,

1. A DCFM is more important when many actors are interested in participating. On the same hand, more actors will be interested to participate in an important DCFM. (Circular argument)

2. The interest of an actor in a DCFM increases as the utility gained by participating increases.

3. The actors who gain more utility will become powerful.

4. Powerful actors are interested in an important DCFM. On the same hand, important DCFMs grab the attention of powerful actors. (Circular argument)

5. An actor needs control over the event to become powerful. On the same hand, a powerful actor would assert greater control over the DCFM. (Circular argument)

These relations are developed more rigorously as postulates and mathematical formulations in the next section.

\subsection{Postulates}

A Deviant Cyber Flash Mob (DCFM), which is an instance of the cyber collective action, could have either of the two outcomes, i.e., success (1) or failure (0) to achieve its goal (Coleman, 1973). In order for us to know whether a DCFM will succeed or not, we propose five postulates that capture the relations between the factors identified in section 3.1 above.

\section{Postulate 1:}

If the importance (Im) of DCFM increases, then the interest (I) of the actors to participate increase. Using the logical implication symbol $(\rightarrow)$, this relation can be expressed as:

$$
\text { Importance }(I m) \rightarrow \text { Interest }(I)
$$

If the number of interested (I) actors in a DCFM 
Table 1 The Symbols Used in the Methodology With Their Meaning

\begin{tabular}{|c||c|}
\hline \multicolumn{1}{|c||}{ Symbol } & Meaning \\
\hline Im & Importance of the DCFM \\
\hline C & The control of an actor over DCFM \\
\hline U & The utility the node gets from the DCFM outcomes \\
\hline I & The interest of the nodes interested in the DCFM \\
\hline P & The power of the node \\
\hline J & Actor (node) \\
\hline
\end{tabular}

increase, then the importance (Im) of the DCFM increases. Using the logical implication symbol and logical equivalence symbol $(\leftrightarrow)$, this relation can be expressed as:

$$
\begin{gathered}
\text { Interest }(I) \rightarrow \text { Importance }(\text { Im }) \\
\therefore \text { Importance }(\text { Im }) \leftrightarrow \text { Interest }(I)
\end{gathered}
$$

\section{Postulate 2:}

If the amount of utility (U) gained by participating increases, then the interest (I) of an actor in the DCFM will increase. This relation can be expressed as:

$$
\operatorname{Utility}(U) \rightarrow \text { Interest }(I)
$$

\section{Postulate 3:}

If the amount of utility (U) gained by participating in the DCFM increases, then the actor's power $(\mathrm{P})$ will increase. This relation can be expressed as:

$$
\operatorname{Utility}(U) \rightarrow \text { Power }(P)
$$

\section{Postulate 4:}

If the actor is powerful (P), then (s)he will be interested in important (Im) DCFMs. This can be expressed as:

$$
\operatorname{Power}(P) \rightarrow \text { Importance }(\text { Im })
$$

If the DCFM is important (Im), then powerful (P) actors will be interested in participating. This relation can be expressed as:

$$
\operatorname{Importance}(\operatorname{Im}) \rightarrow \operatorname{Power}(P)
$$

$$
\therefore \operatorname{Power}(P) \leftrightarrow \text { Importance }(\operatorname{Im})
$$

\section{Postulate 5:}

If the actor is powerful (P), then (s)he will assert more control (C) on the DCFM. This relation can be expressed as:

$$
\operatorname{Power}(P) \rightarrow \operatorname{Control}(C)
$$

If the actor asserts more control (C) on the DCFM, then (s)he will be powerful $(\mathrm{P})$. This can be expressed as:

$$
\begin{aligned}
\text { Control }(C) & \rightarrow \text { Power }(P) \\
\therefore \operatorname{Power}(P) & \leftrightarrow \operatorname{Control}(C)
\end{aligned}
$$

The above postulates lead to the following formulations:

$$
\begin{gathered}
\text { Power }(P)=f(C, \text { Im }) \\
\text { Importance }(\text { Im })=f(\text { Interest }) \\
\text { Interest }(I)=\left|U_{\text {outcome } 1}-U_{\text {outcome } 0}\right| \\
\therefore \text { Power }(P)=f\left(C,\left|U_{\text {outcome } 1}-U_{\text {outcome } 0}\right|\right)
\end{gathered}
$$

Or,

$$
\therefore \text { Power }(P)=f(C, I)
$$

We posit that in order for a DCFM to succeed it needs to have many powerful actors interested in outcome (1). The sum of the powers of all the actors that are interested in the DCFM will give the amount of importance of that DCFM. 


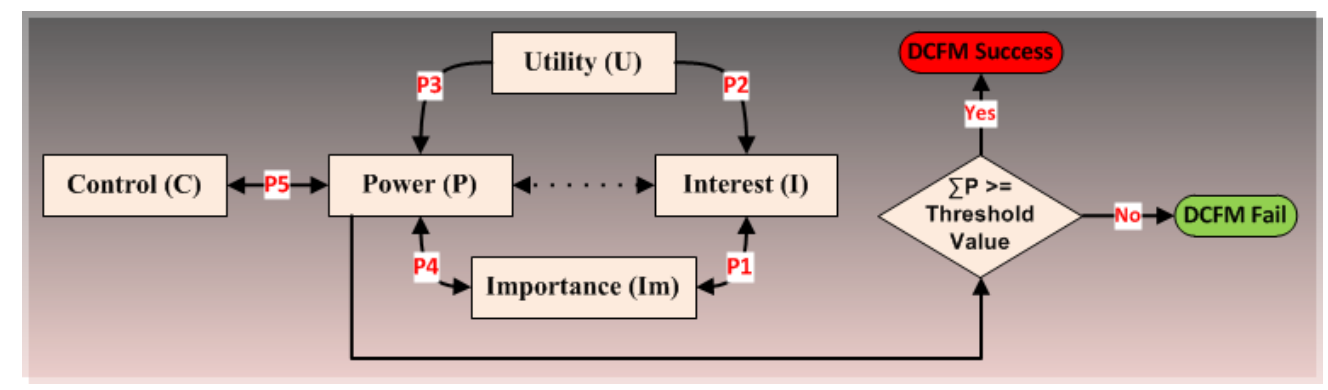

Figure 2 Postulates Showing all the Factors that Help in Determining the Outcome of a DCFM, i.e., Success or Failure.

If that amount of the summation of power equal to a threshold value (which can be calculated from the historical data of known cyber flash mobs that succeeded in the past) then it will be easy to determine whether a DCFM is going to succeed or not.

$$
\text { Im }=\sum_{1}^{m} P_{j} \geqslant \text { Threshold Value }
$$

The summation of powers will be a scalar value that shows how many actors (nodes) control the DCFM and are interested in the outcome 1 (because their utility will increase). Figure 2 shows all the postulates together. Next, we discuss the two cases of success and failure of DCFM in more depth.

\subsection{The Case of DCFM-Success}

To model the formation of a DCFM, it is essential to understand the source of motivation of the individuals that coordinate the act. Shared orientations among individuals often form the basis for motivation resulting in collective actions (Melucci, 1989) (Maheu, 1995). Shared orientations among individuals induce a sense of belongingness to the group giving rise to the group's collective identity. Social dimensions (Tang \& Liu, 2010), such as affiliations, interests, time, location, among others, are the shared orientations that govern the relationships among individuals coordinating a DCFM. Individuals may be connected along one or more social dimension, resulting in multiple shared orientations and hence a stronger collective identity (see Figure 3). It is important to note that such relations are supra-dyadic and multidimensional that are best modeled using hypergraph (Bonacich et al., 2004).

Simple graphs, although efficiently capture the dyadic relations among a set of nodes, are severely challenged in modeling supra-dyadic and multidimensional relations commonplace in DCFM settings. To illustrate these limitations of simple graphs, let's consider a collaboration network represented using a simple graph, where nodes denote authors and edges denote collaborations between the authors. Such a representation would tell us whether any two authors have collaborated or not. However, we cannot know whether three or more authors connected to each other collaborated on the same article. A bipartite graph can possibly be used to address this limitation by creating two different sets of nodes one denoting authors and the other denoting articles. The edges connecting the nodes across the two sets would denote the collaboration relationship among authors. However,

1. Such a representation does not allow studying network properties that require homogeneity among nodes, e.g., connectivity, centrality, and other structural/topological properties.

2. Such a representation only allows us to model the situations where relations among the actors are governed by a single common process. Relationships governed by multiple processes such as, the relationships between actors coordinating an act based on time and location of the event and their 


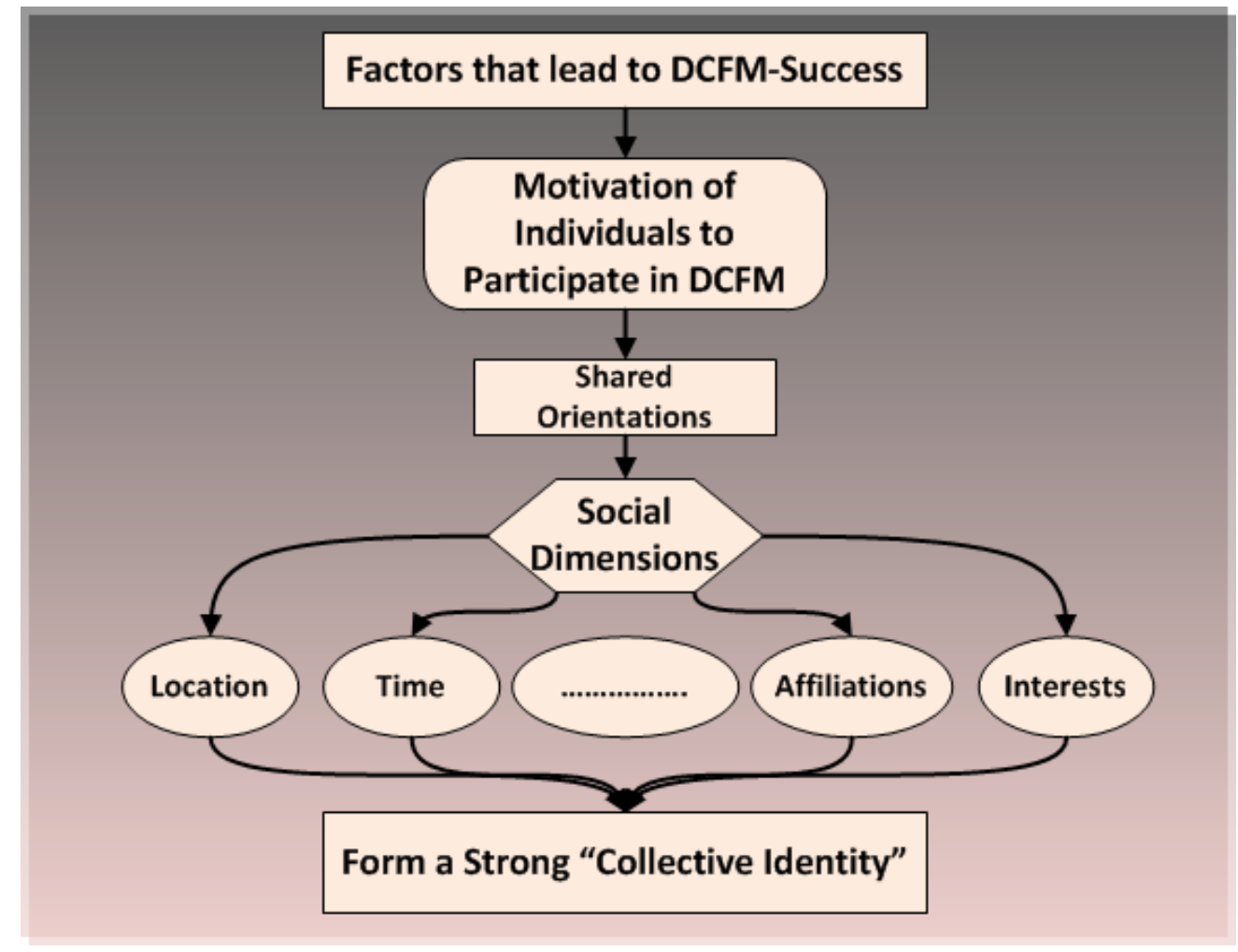

Figure 3 Factors That Lead to The Case of DCFM-Success.

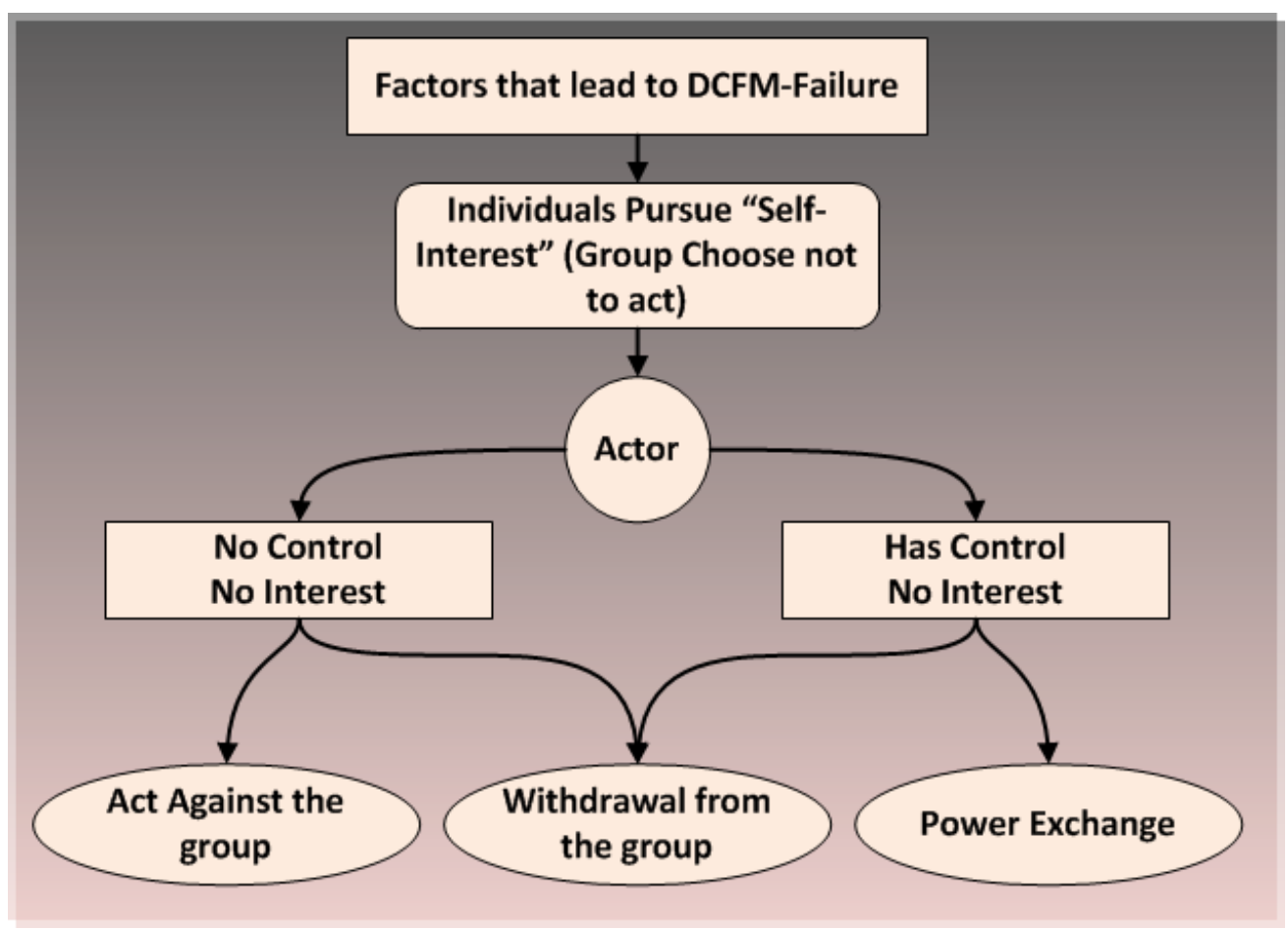

Figure 4 Factors That Lead to The Case of DCFM-Failure. 
affiliations could not be modeled by a single bipartite graph. Using n-partite graphs to model $n$-processes governing relations between actors is a possible but extremely complicated and unscalable solution.

So for such a complicated system we represented it using hypergraph notation because simple and bipartite or n-partite graph would not be sufficient to represent multidimensional and supra-dyadic relations that this system has (Estrada \& Rodriguez-Velazquez, 2006) (Bonacich et al., 2004).

\subsection{The Case of DCFM-Failure}

In his book entitled, "The Logic of Collective Action", Mancur Olson (Olson, 1977) put forward a single basic premise of collective action: "...individual rationality is not sufficient for collective rationality..." (Sandler, 1992). Olson's classic book (Olson, 1977) is mostly concerned with explaining and illustrating how collective failure results when individuals pursue self-interest. Olson's argument is essentially based on the assumption that every individual acts rationally, but if the individuals as a group chooses not to act rationally-with respect to individual costs and benefits-no collective action would occur. So, if an actor has control on DCFM, but does not have an interest in the success of DCFM then the actor has two choices, i.e., (s)he either withdraws from the DCFM or assert power exchange with other members of DCFM (to gain control over other events (DCFMs) or to gain social capital) (see Figure 4). By doing so the social capital of the individual will increase while the power on that DCFM might decrease. Social Capital is defined as "the value that one gains from personal connections such as membership in a family, an ethnic association, elite clubs, or other solidarity groups", as stated by the French economic and cultural sociologist Pierre Bourdieu (Coleman, 1973) (Coleman, 1966) (Bourdieu, 2002) (Ellison et al., 2007). It should be noted that an actor may lose interest in the DCFM's success, if (s)he does not perceive any gain in utility by acting in the DCFM.

If some of the actors in the DCFM are not interested in participating and they do not have control over the outcome then they will have two choices, i.e., either they withdraw or withdraw and act against the group (Coleman, 1973) (see Figure 4). DCFMs can have two possible models: a flat model when the benefits/utilities of the action are equally distributed between all the actors (nodes) who are participating in the collective action. Or, DCFMs could assume a hierarchical model for distribution of the benefits/utilities of the action. In such a hierarchical model, benefits/utilities are disproportionately distributed among the group members. Further, higher the rank of the member the more benefits/utilities the member has. Imaginably, withdrawal of actors from a DCFM with a hierarchical model (especially at the top of the pyramid) will have a bigger effect than the withdrawal of the individual from a DCFM with a flat model.

\subsection{Proposed Conceptual Framework}

First, DCFM data need to be collected from online social networks. Second, this data need to be explored to find out what kind of information we can extract about the users (i.e. identify the shared orientations between group members like social dimensions such as their interest, location, time, and affiliations). Third, this data need to be explored to find out what kind of information we can extract about the DCFM itself (i.e. the number of users involved in that flash mob, whether it succeeds or not, etc.). The more shared orientations that exist among the members of the group the stronger is the collective identity (Klandermans et al., 2002) because shared orientations among individuals induce a sense of belongingness to the group giving rise to the group's collective identity. Melucci (Melucci, 1996) argues that the collective identity formation is the intermediate process for the manifestation of contemporary forms of collective actions in the information age. Figure 5 illustrates the proposed conceptual framework.

After that we will use hypergraph to represent this complex system. Formally, a hypergraph is a generalization of a graph, where an edge can 


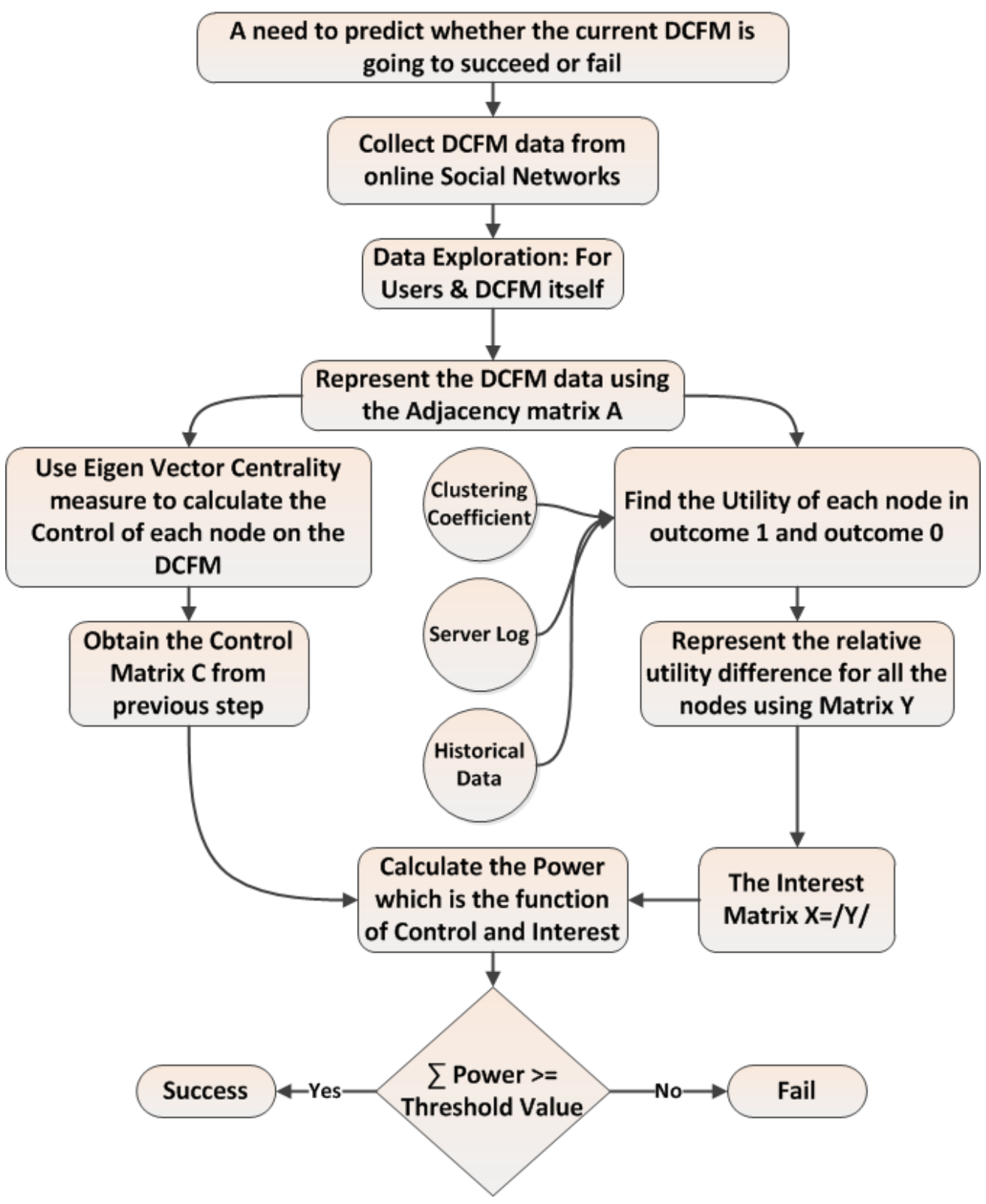

Figure 5 Proposed Conceptual Framework Illustrating a Step-wise Methodology to Predict the Outcome of DCFMs.

connect any number of vertices. A hypergraph $\mathrm{H}$ is a pair $\mathrm{H}=(\mathrm{X}, \mathrm{E})$ where $\mathrm{X}$ is a set nodes or vertices, and $\mathrm{E}$ is a set of non-empty subsets of X called hyperedges (Berge \& Minieka, 1973). A simple graph can be considered as a special case of hypergraph, where each hyperedge has a cardinality of 2 . So let A be the Incidence matrix $(m \times n)$ of the social network (DCFM data that contain users and the relations between them), where rows represent nodes (vertices) and columns represent hyperedges (relations). Matrix A will be used to identify the motivation factors (shared orientations "Social Dimensions"). For each node we need to determine whether it is interested in outcome 1 or outcome 0 (the question whether the node's utility will increase or decrease by each outcome). The utility of the actors (nodes) of the deviant cyber flash mob can be estimated from: 
1. Historical data (examine the nodes of the deviant cyber flash mob historically participated in previous DCFM. If they did participate in that flash mob that indicate a strong interest of those nodes in acting in the current cyber flash mob and that their utility will increase by participating),

2. Server logs.

3. Clustering coefficient (The higher the clustering coefficient the more that node share common orientation and is willing to increase its utility).

Let $\mathrm{Y}$ be the relative utility difference matrix $(m \times n)$ of the network where $y_{j i}$ will have positive value if actor $\mathrm{j}$ favor participation based on hyperedge i. Similarly $y_{j i}$ will have negative value if actor $\mathrm{j}$ favor not to participate based on hyperedge i. $U_{j 1 i}$ is the utility of actor $\mathrm{j}$ gained by participating in the DCFM from hyperedge i. $U_{j 0 i}$ is the utility of actor $\mathrm{j}$ gained by not participating in the DCFM from hyperedge i, such that:

$$
y_{j i}=\frac{U_{j 1 i}-U_{j 0 i}}{\sum_{i}\left|U_{j 1 i}-U_{j 0 i}\right|}
$$

\section{A DCFM SCENARIO}

To study the proposed model's efficacy, we present a DCFM scenario. Let the DCFM scenario be - On March 15, 2014 at 11 am, all students who study at University Z, their age is more than 30, they live in Little Rock AR, and have red cars should go to Walmart Parking lot which is located in Dallas TX, and dance in the parking lot. Each participant will get $\$ 300$ for participating in this event.

This event (DCFM) has two outcomes:

1. Participate, Success (1)

2. Not participate, Fail (0)

Also this DCFM has two hyperedges (i)

1. Cost

2. Time
Actor $\mathrm{j}$ has utility by participating (1) and also has utility by not participating (0).

\section{Case 1}

- Actor $\mathrm{j}$ utility if he decided to participate (1) in this DCFM:

1. If the trip will cost actor $\mathrm{j} \$ 500$ then $(\$ 500$ - $\$ 300$ actor $\mathrm{j}$ will gain by attending $=\$ 200$ ) So Actor $\mathrm{j}$ will lose $\$ 200$.

2. Because of the time of the trip Actor $\mathrm{j}$ will miss his midterm exam. (if actor j midterm exam in the same date)

- Actor $\mathrm{j}$ utility if he decided not to participate (0):

1. Actor j will not lose $\$ 200$.

2. Actor $\mathrm{j}$ will not miss his midterm exam.

The relative utility difference will be negative because:

$$
\begin{gathered}
y_{j \cos t}=\frac{U_{j 1 \cos t}-U_{j 0 \cos t}}{\sum_{\text {cost }}\left|U_{j 1 \cos t}-U_{j 0 \cos t}\right|} \\
y_{j \cos t}=\frac{0-1}{\sum_{\text {cost }}|0-1|} \\
y_{j \cos t}=-1
\end{gathered}
$$

$$
\begin{gathered}
y_{j \text { time }}=\frac{U_{j 1 \text { time }}-U_{j 0 t i m e}}{\sum_{\text {time }}\left|U_{j 1 \text { time }}-U_{j 0 \text { time }}\right|} \\
y_{j \text { time }}=\frac{0-1}{\sum_{\text {time }}|0-1|} \\
y_{\text {jtime }}=-1
\end{gathered}
$$

$$
\mathrm{Y}=\left[\begin{array}{ccccc} 
& j & . . & . . & V_{n} \\
\text { Cost } & -1 & . . & . . & . . \\
\text { Time } & -1 & . . & . . & . . \\
. . & . . & . . & . . & . . \\
. . & . . & . . & . . & . .
\end{array}\right]
$$


- Actor $\mathrm{j}$ utility if he decided to participate

(1) in this DCFM:

1. If the trip will cost him $\$ 200$ and he will get $\$ 300$ that means he will gain $\$ 100$.

2. He is free on this time.

- Actor $\mathrm{j}$ utility if he decided not to participate $(0)$ :

1. He will not gain $\$ 100$.

2. He will be bored and miss all the fun.

In this case the relative utility difference will be positive because:

$$
\begin{gathered}
y_{j \operatorname{cost}}=\frac{U_{j 1 \text { cost }}-U_{j 0 \text { cost }}}{\sum_{\text {cost }}\left|U_{j 1 \text { cost }}-U_{j 0 \text { cost }}\right|} \\
y_{j \text { cost }}=\frac{1-0}{\sum_{\text {cost }}|1-0|} \\
y_{j \text { cost }}=+1 \\
y_{j \text { time }}=\frac{U_{j 1 \text { time }}-U_{j 0 t i m e}}{\sum_{\text {time }}\left|U_{j 1 \text { time }}-U_{j 0 t i m e}\right|} \\
y_{j t i m e}=\frac{1-0}{\sum_{\text {time }}|1-0|} \\
y_{j \text { time }}=+1
\end{gathered}
$$

So,

$$
\mathrm{Y}=\left[\begin{array}{ccccc} 
& j & . . & . . & V_{n} \\
\text { Cost } & +1 & . . & . . & . . \\
\text { Time } & +1 & . . & . . & . . \\
. . & . . & . . & . . & . . \\
. . & . . & . . & . . & . .
\end{array}\right]
$$

Going back to the proposed conceptual framework, let $\mathrm{X}$ represents the interest matrix $(m \times n)$ of the nodes in the network. We take the absolute value of $y_{j i}$ and use it to represent the interest of a node in the flash mob $x_{j i}$ (The interest of an actor in a flash mob is his utility difference from both the outcomes will make to him or the importance of the outcome for him).

$$
x_{j i}=\left|y_{j i}\right|
$$

$$
\sum_{i} x_{j i}=1.0
$$

From the interest matrix $\mathrm{X}$ now we know how many nodes are interested in outcome 1 and how many nodes are interested in outcome 0 .

We also need to calculate the control $\left(C_{j i}\right)$ of each node on the DCFM. We use the control matrix $\mathrm{C}(m \times n)$ to represent that and $C_{j i}$ values can be obtained by using the eigenvector centrality measure (Bonacich et al., 2004) .

$$
\text { Centrality measure of nodes } C_{N}=A A^{T}
$$

Centrality measure of hyperedges $C_{E}=A^{T} A$

Now the importance of a DCFM (Ludlow, January 13,2013 ) which is a function of the control and interest can be obtained using the following algebraic expression:

Importance $(\operatorname{Im})=\sum_{1}^{m} P_{j} \geqslant$ Threshold Value

In matrix notation, when we have a system of m-equations:

$$
\operatorname{Importance}(\operatorname{Im})=X . C_{N}
$$

\section{CONCLUSION \& FUTURE WORK}

In this study, we focused on the flash mob phenomena and showed the different forms and scopes that it can assume. We developed a conceptual model for the deviant cyber flash mob (DCFM) grounded in the theories of collective action and collective identity formation. Mathematical constructs of hypergraph are leveraged to represent the complex multi-dimensional and supra-dyadic relations manifested in the DCFM social networks. We identified the necessary conditions and motivations that lead to the emergence of these phenomena such as interest and control. By studying the factors that lead to the success and failure of a DCFM, we envision the development of a predictive model. To the best of our knowledge, this is the first study 
examining the DCFM behavior with groundings in social science theories.

Although the model's efficacy is demonstrated through a DCFM scenario, our immediate future directions include empirical validation of the model and its sensitivity analysis vis-a-vis the parameters (e.g., power threshold, etc.) using real-world data for DCFMs. This research will help understand and advance cybersecurity strategies at a fundamental social and behavioral level. The research is of potential interest to sociologists, anthropologists, and information system experts exploring the influence of social systems on user behaviors; studying ties between people, technology, and institutions; examining organizational structures, roles, and crowd processes.

\section{ACKNOWLEDGEMENTS}

This material is based upon work supported by the U.S. Office of Naval Research under Grant Number N000141410489 and U.S. National Science Foundation's Socio-Computational Systems and Human Centered Computing programs under Award Numbers IIS-1110868 and IIS1110649 .

\section{REFERENCES}

Ackerman, G., et al. (2013). The "new" face of transnational crime organizations (tcos): A geopolitical perspective and implications to us national security. Calhoun.

Agarwal, N., Lim, M., \& Wigand, R. (Eds.). (2014). Online collective action:

Dynamics of the crowd in social media. Springer.

Agarwal, N., et al. (2012). Raising and rising voices in social media: A novel methodological approach in studying cyber-collective movements. Business $\&$ Information Systems Engineering, 4(3), 113--126.

Becker, G. S. (1976). The Economic Approach to Human Behavior. University of Chicago Press.
Berge, C., \& Minieka, E. (1973). Graphs and hypergraphs (Vol. 7). North-Holland publishing company Amsterdam.

Bonacich, P., et al. (2004). Hyper-edges and multidimensional centrality. Social networks, 26 (3), 189--203.

Bourdieu, P. (2002). Readings in economic sociology. In N. W. Biggart (Ed.), (Vol. 8, p. 280-291). Blackwell.

Coase, R. H. (1937). The Nature of the Firm. Economica, 4 (16), 386--405.

Coleman, J. S. (1966). Foundations for a theory of collective decisions. American Journal of Sociology, 71.

Coleman, J. S. (1973). The mathematics of collective action. In (p. 61-90). Transaction Publishers.

Cyveillance. (December 2, 2013). Bashmobs: Using social media to organize disruptive activity. In Cyveillance a qinetiq company (url: https://blog.cyveillance.com/generalcyberintel/bashmobs-using-social-mediato-organize-disruptive-activity). Last checked: August 14, 2014.

Digits. (February 21, 2012). Wsj's facebook pages target of 'comment flashmob'. In The wall street journal (url: http://blogs.wsj.com/digits/2012/02/21/wsjsfacebook-pages-target-of-commentflashmob/). Last checked: August 15, 2014.

Dye, J., \& Finkle, J. (May 9, 2013). Us charges eight in $\$ 45$ million cybercrime scheme.

In Cnbc.com (url: http://www.cnbc.com/id/100724220).

Last checked: August 14, 2014.

Ellison, N. B., et al. (2007). The benefits of facebook "friends:" social capital and college students' use of online social network sites. Journal of Computer-Mediated Communication, 12(4), 1143--1168.

Estrada, E., \& Rodriguez-Velazquez, J. A. (2006). Subgraph centrality and clustering in complex hyper-networks. Physica A: Statistical Mechanics and its Applications, 364, 581--594.

Ferree, M. M. (1992). Frontiers in social 
movement theory. In A. D. Morris \& C. M. Mueller (Eds.), (p. 29-52). Yale University Press.

Holbrook, B. (July 19, 2013). Lbpd prepared for potential bash mob event. In Everything long beach (url: http://www.everythinglongbeach.com/lbpdprepared-for-potential-bash-mob-event/). Last checked: August 15, 2014.

Johnston, H., et al. (1994). Identities, grievances, and new social movements. New social movements: From ideology to identity, 3--35.

Kerbo, H. R. (1982). Movements of crisis and movements of affluence a critique of deprivation and resource mobilization theories. Journal of Conflict Resolution, $26(4), 645--663$.

Kirkland, C. (December 21, 2011). 12 great examples of flash mobs. In Econsultancy (url: http://econsultancy.com/blog/854812-great-examples-of-flash-mobs). Last checked: August 15, 2014.

Klandermans, B., et al. (2002). Identity processes in collective action participation: Farmers' identity and farmers' protest in the netherlands and spain. Political Psychology, 23(2), 235--251.

Ludlow, P. (January 13, 2013). What is a 'hacktivist'? In Opinionator (url: http://opinionator.blogs.nytimes.com/2013 /01/13/what-is-a-hacktivist/). Last checked: August 15, 2014.

Maheu, L. (1995). Social movements and social classes: The future of collective action (Vol. 46). SAGE Publications Ltd.

Melucci, A. (1989). Nomads of the present: Social movements and individual needs in contemporary society. Temple University Press.

Melucci, A. (1996). Challenging codes: Collective action in the information age. Cambridge University Press.

Newman, M. E. (2006). Modularity and community structure in networks. Proceedings of the National Academy of Sciences, 103(23), 8577--8582.

Nicholson, J. A. (2005). Fcj-030 flash! mobs in the age of mobile connectivity. The Fibreculture Journal-Mobility.

Olson, M. (1977). The logic of collective action: public goods and the theory of groups. Harvard University Press.

Oxford-Dictionary. (July 8, 2004). Definition of flash mob from oxford english dictionaries online. In Oxford english dictionaries (url: http://www.oxforddictionaries.com/definition /english/flash-mob). Last checked:

August 22, 2014.

Reporter, D. M. (April 4, 2011). Feathers fly and new york's union square becomes a bedding battleground as world celebrates international pillow fight day. In Mail online (url:

http://www.dailymail.co.uk/news/article1372841/international-pillow-fight-daycelebrated-worldwide-feathers-fly-newyork.html). Last checked: August 13, 2014.

Rubinstein, A. (1979). Equilibrium in Supergames with the Overtaking Criterion. Journal of Economic Theory, $21(1), 1--9$.

Sandler, T. (1992). Collective action: Theory and applications. University of Michigan Press.

Sandler, T., \& Tschirhart, J. (1980). The Economic Theory of Clubs: An Evolutionary Survey. Journal of Economic Literature, 43, 1481-1521.

Snow, D. A., et al. (1986). Frame alignment processes, micromobilization, and movement participation. American sociological review, 464--481.

Tang, L., \& Liu, H. (2010). Toward predicting collective behavior via social dimension extraction. Intelligent Systems, IEEE, 25(4), 19--25.

Warr, P. G. (1982). Pareto Optimal Redistribution and Private Charity. Journal of Public Economics, 19(1), 131--138.

Warr, P. G. (1983). The Private Provision of a Public Good is Independent of the Distribution of Income. Economics Letters, 13(2), 207--211. 
Wasik, B. (December 16, 2011). Riot:

Self-organized, hyper-networked revoltscoming to a city near you. In Wired (url:

http://www.wired.com/2011/12/ff_riots/all/1).

Last checked: August 15, 2014.

Zald, M. N., \& McCarthy, J. D. (1979). The dynamics of social movements: resource mobilization, social control, and tactics.

Winthrop Publishers. 
